\title{
The HPV Action story
}

\author{
By Peter Baker, Campaign Director for HPV Action
}

$\mathrm{O}$

n 24 July 2018, Public Health

Minister Steve Brine took fewer than 30 seconds to inform the House of Commons that boys would now be covered by the national HPV vaccination programme.

His short statement marked the culmination of a five-year campaign led by HPV Action, a partnership of 51 organisations including the British Dental Association (BDA) and a range of groups dedicated to confronting the rising incidence of oral cancers.

We launched in 2013 with the aim of achieving gender-neutral vaccination in the UK. Our main target was the government's vaccination advisory committee (known as JCVI or Joint Committee on Vaccination and Immunisation) which in the same year had begun an assessment of whether boys should be vaccinated.

At that time, the JCVI was expected to make a decision in 2015. This was then postponed to 2017 before finally being made this year.

Now that we have achieved our goal, it is worth reflecting how we did so. Victories such as these are not common in the public health field.

HPV Action's advocacy work was almost entirely funded by its own members and no funding came from the vaccine manufacturers or any other organisation with a commercial interest. This meant that money was tight

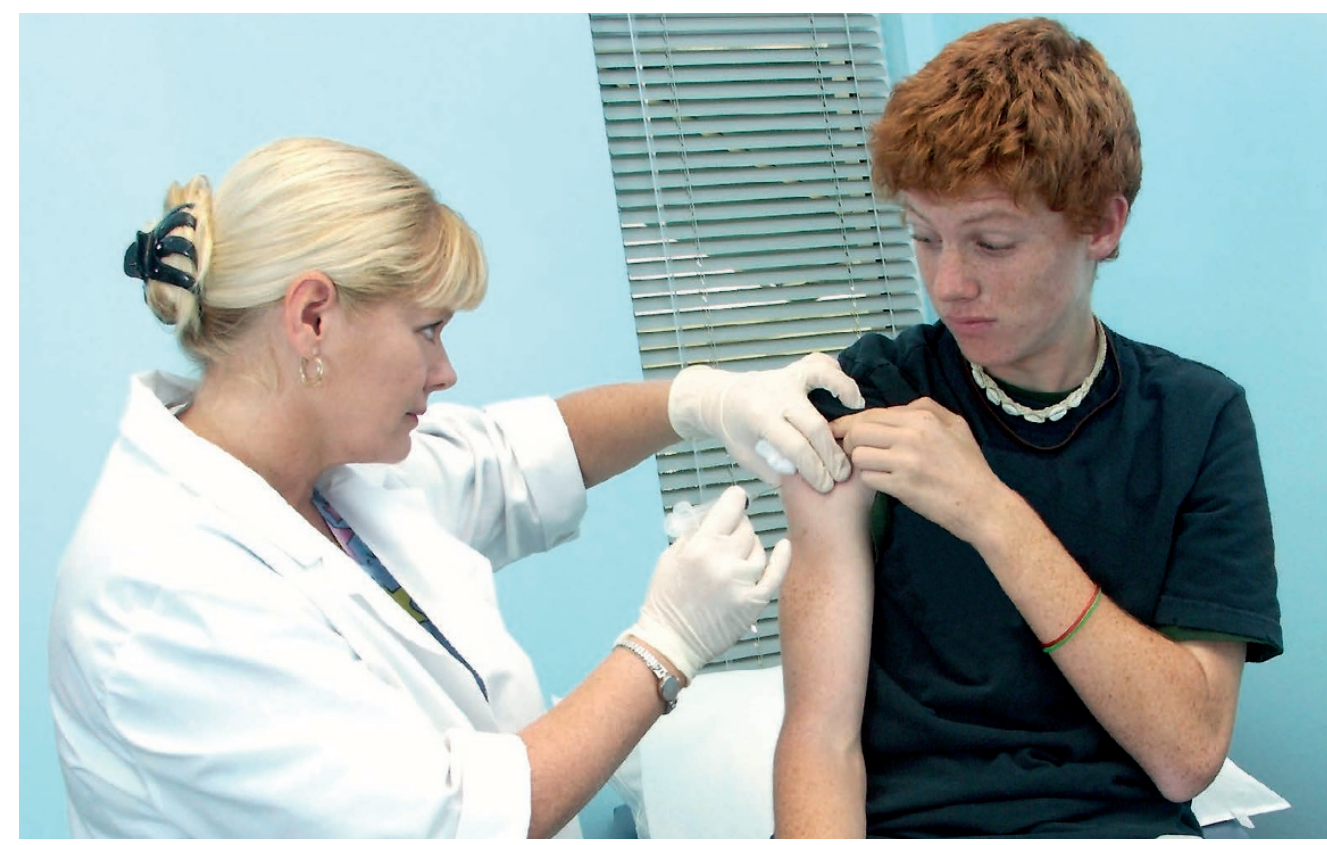

to large and influential national organisations. HPV Action had a single and easily-understood goal so did not get distracted by multiple aims or internal disagreements about priorities.

Deciding to remain a loose association of organisations rather than a legally-constituted entity also meant there were minimal overhead costs and few governance issues to resolve. HPV Action's finances were managed by a member organisation - the Oral Health Foundation - and as the only member of

\section{'The vaccination of boys as well as girls will lead to a significant drop in the number of cancer cases' - Peter Baker}

- the whole five-year campaign was delivered for around $£ 60,000$ - but there could be no accusations of a conflict of interest.

In the first few years, HPV Action set out to be inclusive and to reach out to as many potential members as possible. These included organisations with an interest in cancer, sexual health, men's health, gay men's health and public health as well as oral health. Its members also ranged from small local groups staff, I worked on a freelance basis.

Our tactics were equally straightforward and included making the case to opinionleaders in the field, for example, through journal articles and conference presentations, building support among politicians from all parties, lobbying ministers directly and engaging with the officials supporting JCVI.

A large number of MPs supported the call for action following lobbying by HPV Action.
Of particular importance were the endorsements by the chairs of several influential all party groups (APGs), including John Baron from the Cancer APG and Sir Paul Beresford from the All Party Group for Dentistry and Oral Health.

Early day motions and parliamentary questions were tabled and MPs briefed for debates in both the Commons and Lords.

Several meetings were held with the JCVI secretariat and the Public Health England officials working with JCVI. Detailed responses were made to JCVI consultations.

Throughout, HPV Action highlighted concerns with JCVI's cost-effectiveness modelling and also raised wider issues that needed to be taken into account, not least sex discrimination. Huge importance was attached to gathering and disseminating the best-available evidence.

One of HPV Action's members, the Throat Cancer Foundation, began its own legal proceedings against JCVI and the Department of Health and Social Care on the grounds of sex discrimination. The decision was made to vaccinate boys before this came to court but the threat of judicial review no doubt added to the pressure on officials and ministers. 
4 Media coverage was sought wherever possible. HPV Action was fortunate to receive some pro bono PR support from the agency Street and Co and several of our member organisations were actively engaged in the media work, not least the BDA.

Stories were developed which created new angles, such as a report on the views of Nobel Prize winner Professor Harald zur Hausen (the scientist who discovered the link between HPV and cervical cancer) and a national survey of dentists and doctors.

Organised with the help of the BDA, Faculty of General Dental Practice and British Medical Association (BMA), the survey found that $95 \%$ of respondents thought boys should be vaccinated. In the last six months of the campaign, the Mail on Sunday became a staunch supporter and ran a series of hard-hitting articles.
There were challenges with the campaign of course. Limited funding was a continual concern and particularly hampered attempts to engage parents and encourage them to lobby their MPs.

A small number of member organisations shouldered the main burden of funding the campaign which at times caused some tension and the possibility of HPV Action collapsing before its goal had been achieved. An online petition, begun in 2013, never came close to its target of 100,000 signatures and was effectively side-lined.

Organisations and individuals not under the HPV Action umbrella also played an important role. Particular thanks here are due to the BMA and Professor Margaret Stanley of Cambridge University, now President-Elect of the International Papillomavirus Society. Many individual and influential clinicians and academics also helped to tip the scales.

HPV Action will now be turning its attention to ensuring that implementation of the boys' programme is quick and effective.

A national rollout in September 2019 is essential and it is also vital that boys and their parents receive appropriate educational information about the vaccine. The opportunity should be taken to tackle the major variations in vaccine uptake between local authority areas that currently exist in the girls' programme.

Our supporters in the dental profession and all members of HPV Action can justifiably feel proud of their achievement. The vaccination of boys as well as girls will lead to a significant drop in the number of cancer cases as well as impacting on other HPVrelated diseases. It is a major step forward in public health in the UK.

\section{Regulator bans KFC and Kellogg's adverts from targeting children}

The Advertising Standards Authority (ASA) has upheld complaints against two brands for adverts for unhealthy food aimed at children.

The complaints, submitted by the Obesity Health Alliance (OHA) and Children's Food Campaign (CFC), include:

- An advert for a KFC [Kentucky Fried Chicken] 'Mars Krushem' milkshake drink placed in a phone box directly outside a primary school. This broke the Committee of Advertising Practice (CAP) code rule which states adverts from products high in fat, sugar and salt (HFSS) should not be placed in areas where the audience is likely to be disproportionally made up of children

- An advert for 'Coco Pops Granola Cereal' shown on a children's TV channel. The product (manufactured by Kellogg's) advertised is not classed as an HFSS, but the OHA argued that the advert had the effect of promoting Coco Pops cereal due to the use of branding and the character Coco the Monkey which is highly associated with the original Coco Pops cereal.

Caroline Cerny, Alliance Lead at the OHA, said: 'The ruling on Coco Pops
Granola provides an important precedent for junk food marketing.

'These adverts are designed specifically to appeal to children with fun cartoon characters and catchy jingles. This ruling recognises that, even though the product shown is classified as 'healthier', the advert used all the same features as adverts for original Coco Pops cereal and therefore essentially promoted the 'less healthy' product, which is not acceptable.

'We are very supportive of brands reformulating their products to reduce sugar and overall calories, but they must market them responsibly.'

Children's Food Campaign Co-ordinator Barbara Crowther added: 'We are pleased these complaints have been upheld, but they are the tip of the iceberg when it comes to non-compliance with the rules.

'We know at least seven other complaints about fast food and confectionery ads on bus stops and telephone boxes next to schools have been submitted to the ASA. This indicates that brands are simply flouting the rules, hoping no-one will bother to complain, and safe in the knowledge there are no meaningful sanctions for non-compliance anyway'.

A spokesperson for Kellogg's said: 'We are disappointed with this decision as we ensured throughout the advert that we were

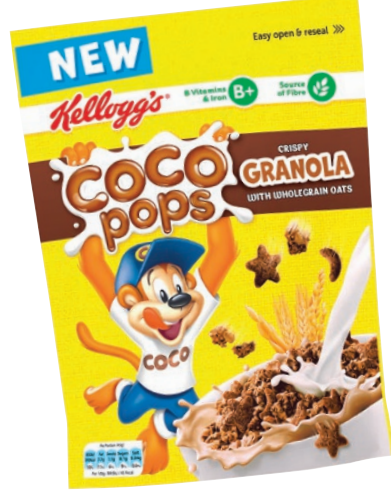

only promoting the Coco Pops Granola product, a cereal that can be advertised in children's airtime.

'It's particularly surprising when a ruling from the television regulator OFCOM published on Monday confirmed that an advert for the same product was not in breach of the advertising code.'

The recently published chapter 2 of the Government's Childhood Obesity Plan ${ }^{1}$ includes an intention to introduce a $9 \mathrm{pm}$ watershed on junk food adverts on TV, with a similar level of protection applied online, and a commitment to consider whether the current self-regulatory approach to advertising rules provides protection to children from HFSS marketing.

Department of Health and Social Care. Childhood obesity: a plan for action, chapter 2. Available at https://www.gov.uk/government/publications/childhood-obesity-a-plan-for-action-chapter-2 (accessed 6 August 2018). 